\title{
Compreendendo os resultados de aprendizagem em intercâmbios voluntários internacionais
}

Tiago Coutinho Vasconcelos

Mestre em Administração de Empresas

Fundação Instituto Capixaba de Pesquisas em Contabilidade, Economia e Finanças - Fucape

Business School, Espirito Santo, Brasil

tiagocoutinho6@hotmail.com

Bruno Felix von Borell de Araujo

Doutor em Administração de Empresas, Fundação Instituto Capixaba de Pesquisas em Contabilidade, Economia e Finanças - Fucape Business School, Espirito Santo, Brasil

bfelix@fucape.br

\section{Editor Científico: José Edson Lara}

Organização Comitê Científico

Double Blind Review pelo SEER/OJS

Recebido em 30.11.2015

Aprovado em 20.08.2016 


\title{
Resumo
}

Apesar de os estudos sobre o aprendizado de expatriados serem recorrentes, somente recentemente as pesquisas na área do intercâmbio voluntário internacional têm ganhado atenção. Este artigo visa compreender os resultados de aprendizagem em intercâmbios voluntários internacionais. Foi possível evidenciar, por meio de um estudo qualitativo transversal, o aprendizado reportado por voluntários internacionais brasileiros. Foram encontrados 119 eventos distintos de aprendizado em uma amostra de 25 voluntários, e o desenvolvimento pessoal foi a área de aprendizado com maior número de incidentes. Também foram encontrados incidentes relativos aos seguintes resultados de aprendizagem: capacidade de decisão e solução de problemas, sensibilidade cultural, comunicação, perspectiva estratégica, autoconhecimento, habilidades gerenciais e domínio de um conhecimento específico. Os resultados permitem caracterizar o trabalho voluntário internacional como um rico meio de aprendizado, bem como identifica as principais áreas de aprendizado.

Palavras-chave: Voluntário. Intercâmbio Internacional. Desenvolvimento Pessoal. Expatriado.

\section{Understanding the learning results from international volunteer placements}

\begin{abstract}
Although studies on learning of expatriates are common, only recently research in the area of international volunteer placements have gained attention. This article aims to understand the learning outcomes in international volunteer placements. It was possible to show, by means of a transversal qualitative study, the learning reported by Brazilian international volunteers. We found 119 distinct learning events in a sample of 25 volunteers, and personal development was the learning area with the highest number of incidents. We also found incidents related to the following learning outcomes: decision making and problem solving, cultural sensitivity, communication, strategic perspective, self-knowledge, managerial skills and domain specific knowledge. Results characterize international volunteering as a rich means of learning and identifies the main areas of learning.
\end{abstract}

Keywords: Volunteer. International Placement. Personal Development. Expatriate.

\section{La comprensión de los resultados de aprendizaje en los intercambios voluntarios internacionales}

\section{Resumen}

Aunque los estudios sobre el aprendizaje de los expatriados son recurrentes, sólo recientemente la investigación en el área de intercambio voluntario internacional ha 
ganado la atención. Este artículo tiene como objetivo entender los resultados del aprendizaje en los intercambios internacionales de voluntarios. Fue posible demostrar mediante un estudio cualitativo transversal, el aprendizaje reportado por los voluntarios internacionales brasileños. Encontraron 119 eventos diferentes de aprendizaje en una muestra de 25 voluntarios, y el desarrollo personal fue el área de aprendizaje con el mayor número de incidentes. También fueron encontrados incidentes relacionados con los siguientes resultados de aprendizaje: toma de decisiones y resolución de problemas, la sensibilidad cultural, de comunicación, de perspectiva estratégica, el auto-conocimiento, capacidad de gestión y conocimiento de dominio específico. Los resultados caracterizan el trabajo voluntario internacional como un medio de aprendizaje rico e identifica las principales áreas de aprendizaje.

Palabras clave: Voluntarios. Intercambio Internacional. Desarrollo Personal. Expatriado.

\section{Introdução}

O trabalho voluntário internacional é visto como uma ação socialmente valorizada, mas que gera poucos benefícios além da satisfação altruística (Fee \& Gray, 2011). Todavia, há um entendimento compartilhado de que o intercâmbio voluntário internacional (IVI) pode acelerar o desenvolvimento de habilidades e competências, servindo como uma etapa para a formação de profissionais que são atraídos por organizações inseridas em contextos multiculturais (Thomas, 2002; Brook, Missingham, Hocking, \& Fifer, 2007; Fee \& Gray, 2011).

O voluntariado internacional é uma atividade em expansão no cenário contemporâneo. Os dados da Association Internationale des Etudiants en Sciences Economiques et Commerciales (AIESEC), organização que realiza intercâmbios voluntários internacionais, registrou, no ano de 2013, cerca de 23.146 intercâmbios nos 113 países e territórios em que está presente, sendo que destes, 1.625 voluntários são brasileiros (AIESEC Annual Report, 2014). Nas Nações Unidas (ONU), todos os anos, cerca de 7.000 voluntários qualificados e com experiência profissional, com mais de 170 nacionalidades, servem em mais de 140 países. Desses, sessenta por cento servem em países que não são os seus próprios (ONU$B R, 2013)$.

As experiências de trabalho voluntário no exterior apresentam oportunidades de desenvolvimento pessoal e profissional (von Borell de Araujo et al., 2014; Fee \& Gray, 2011). Em geral, grande parte do aprendizado no ambiente de trabalho é 
informal, ocorrendo naturalmente nas situações do dia-a-dia onde aprender não é necessariamente o objetivo principal (Marsick \& Watkins, 2001).

Com os negócios e os profissionais se tornando cada vez mais especializados, a competição por talentos aumenta em intensidade e complexidade (Berlato \& Corrêa, 2017; Santos, Bronzo, Oliveira, \& Resende, 2014; Reis, Fleury, Fleury, \& Zambaldi, 2015, Govindarajan \& Gupta, 2001). Muitas das habilidades desenvolvidas por voluntários internacionais se encaixam em uma classe específica e de interesse do mercado de trabalho (Fee et al., 2015; Black, Morrison, \& Gregersen, 1999a). Essas qualidades chamadas por Black et al. (1999a) como "soft skills" são de difícil aprendizado e desenvolvimento e, não frequentemente encontradas nas pessoas (King \& Raghuram, 2013; Brook et al., 2007).

Entre as habilidades e competências desenvolvidas em um ambiente de trabalho internacional, podem-se citar: comunicação intercultural, habilidades de gestão (como supervisionar e motivar, tolerar ambiguidades e incertezas), além do conhecimento da cultura local e o funcionamento do ambiente internacional dos negócios (Black, Gregersen, Mendenhall, \& Stroh, 1999b; Berthoin, 2000; Bolino \& Feldman, 2000).

Empresas investem recursos qualificando seus profissionais para ocuparem posições no exterior, e alguns estudiosos têm explorado Intercâmbios Voluntários Internacionais (IVIs) como alternativa para o desenvolvimento de habilidades soft e globais (Thomas, 2002; Cook \& Jackson, 2006; Hudson \& Inkson, 2006; Brook et al., 2007; Fee \& Gray, 2011).

Quando se fala em experiência de trabalho realizada no exterior, em geral se foca em expatriados. Pouco se sabe sobre em que aspecto a experiência internacional de voluntariado pode se tornar uma rica fonte de aprendizado e desenvolvimento (Bader \& Schuster, 2015; Polonijo-King, 2004). No sentido de ampliar a contribuição de estudos anteriores (Thomas, 2002; Cook \& Jackson, 2006; Hudson \& Inkson, 2006; Brook et al., 2007; Fee \& Gray, 2011), faz-se necessário compreender não somente como ocorre 0 aprendizado em intercâmbios internacionais, mas também o que é realmente aprendido em tais experiências.

Além do exposto, a associação entre IVI e cidadania global continua não suportada empiricamente (Lyons, Hanley, Wearing, \& Neil, 2012) e não há artigos nacionais sobre o tema (Nascimento, 2012). Desta maneira, o propósito deste 
estudo é responder à seguinte questão: O que indivíduos aprendem durante a experiência internacional de voluntariado?

A partir desse contexto, o presente estudo visa compreender os resultados de aprendizagem obtidos no intercâmbio voluntário internacional e, dessa maneira, permitir que o jovem planeje melhor o seu plano de carreira. $O$ estudo, de natureza qualitativa, foi realizado por meio de entrevistas e análise de conteúdo. Este trabalho contribui para a literatura no sentido de expandir o entendimento do 'como' o processo de aprendizagem ocorre (Thomas, 2002; Brook et al., 2007; Fee \& Gray, 2011) para 'o que' é aprendido.

Nesta pesquisa, será estudada a apreensão de experiências, considerando o caso específico do voluntário internacional brasileiro. Dessa forma, a pesquisa apresenta-se como relevante, especialmente no atual contexto em que os profissionais brasileiros têm se inserido cada vez mais no mercado de trabalho internacional (Araujo et al., 2013) e, por consequência, se veem na condição de buscar um maior desenvolvimento de características desejáveis no ambiente global de trabalho.

\section{Referencial Teórico}

\subsection{A globalização e as implicações para o trabalhador contemporâneo}

A globalização trouxe aumento significativo nas interações entre culturas, sendo esse um dos motivos pelos quais a questão da expatriação é significante (Lee \& Sukoco, 2010). Como as organizações estão expandindo suas ações além das fronteiras, é sugestivo que os gestores lidem com subordinados de outras culturas. Essa rápida internacionalização e globalização têm aumentado a significância da diversidade no ambiente de trabalho e o aumento da complexidade dessas relações exigem um novo perfil profissional (Shen \& Jiang, 2009).

O objetivo das organizações é identificar indivíduos que sejam capazes de operar satisfatoriamente em contextos diversificados. Como existem poucos critérios que avaliam a performance em contextos internacionais (Arasaratnam \& Doerfel, 2005) é importante avaliar corretamente qual tipo de gestor é o mais produtivo nesses ambientes (Van Woerkom \& Reuver, 2009). Estudos apontam características e competências que têm relação direta e mediadora com a performance (Black et al., 1991; Sippola \& Smale, 2007; Ryan et al., 2009; Shen et al., 2009; Van Woerkom \& 
De Reuver, 2009; Lee \& Sukoco, 2010) e, portanto, identificar estruturas que permitam o seu aprendizado e desenvolvimento devem ser estudadas.

\subsection{Trabalho voluntário internacional}

Voluntariar é prestar qualquer tipo de atividade gratuitamente, com o intuito de beneficiar outra pessoa, grupo ou organização (Wilson, 2000). O termo sugere que voluntários não recebem compensação financeira pelos serviços prestados; porém, isso é geralmente incorreto (Fee \& Gray, 2011). Muitos voluntários recebem algum tipo de compensação, mesmo que abaixo do que ganhariam em seus países de origem. O retorno financeiro para os voluntários pode não ser tão atrativo quanto a remuneração de expatriados não-voluntários, porém, há outras recompensas, como por exemplo, o alto grau de desenvolvimento pessoal reportado pelos voluntários (Fee \& Gray, 2011).

Acadêmicos vêm traçando distinção entre profissionais voluntários e turistas voluntários (Simpson, 2004). Os 'profissionais' voluntariam por aproximadamente um ou dois anos e quase sempre recebem algum tipo de pagamento por seu trabalho (mesmo que menor do que receberia no mercado de trabalho). Tendem a ser qualificados em seu campo de atuação e possuem experiência profissional (Ex.: voluntários da $\mathrm{ONU}$ ). Por outro lado, 'turistas voluntários' não recebem nenhum pagamento pelo trabalho e o período do projeto é curto, entre um e seis meses. Eles raramente possuem experiência profissional ou qualificação e pagam valores consideráveis para a agência que organiza a colocação (Wickens, 2011).

Uma vez que os respondentes deste estudo possuem características comuns aos dois grupos ('profissionais' e 'turistas voluntários'), como por exemplo, exercem atividades por um curto período de tempo e possuem qualificação profissional, não será feita distinção entre os termos. Adotaremos todas as experiências voluntárias internacionais como um IVI.

\subsection{Resultados de aprendizagem em experiências internacionais}

O ambiente internacional voluntário apresenta características peculiares no sentido de prover mecanismos de aprendizado aos expatriados (Fee \& Gray, 2011). Os resultados do aprendizado também se apresentam com características de 
portabilidade, ou seja, eles envolvem entendimentos e habilidades que são prontamente transferíveis para outros contextos ou organizações (Berthoin, 2000).

Estudos têm identificado uma variedade de habilidades que voluntários internacionais desenvolvem durante seus intercâmbios que superam o que é reportado pela literatura de expatriados (Bell, 1994; Thomas, 2002; Jones, 2005; Tran \& Nyland, 2013; Cook \& Jackson, 2006; Hudson \& Inkson, 2006; Brook et al., 2007). Esta variedade de habilidades identificadas foi sumarizada por Eraut (2004) em oito grandes áreas: (1) Desenvolvimento pessoal (incluindo confiança, resiliência e valores éticos); (2) Capacidade de decisão e solução de problemas; (3) Sensibilidade cultural; (4) Comunicação (incluindo colaboração e trabalho em equipe); (5) Perspectiva estratégica; (6) autoconhecimento; (7) Habilidades Gerenciais (incluindo mentoria, liderança, coaching e treinamento) e (8) Domínio de um conhecimento específico.

Seguindo a divisão proposta por Eraut (2004), o aprendizado reportado por expatriados dentro da área de desenvolvimento pessoal é: o aumento de produtividade, autossuficiência e confiança (Bell, 1994; Thomas, 2002). A liderança e a gestão de incertezas (Thomas, 2002) acrescentam-se às habilidades de solução de problemas. Dentro do entendimento estratégico e cultural, está o desenvolvimento de comunicação, linguagem (Hudson \& Inkson, 2006; Brook et al., 2007), pensamento estratégico, perspectiva e cidadania global (Thomas, 2002). E por fim, o indivíduo também adquire experiência em gestão de projetos, gestão da diversidade e networking profissional (Shen \& Jiang, 2015; Cook \& Jackson, 2006).

O aprendizado reportado durante a experiência de voluntários internacionais, por outro lado, se mostra mais consistente e amplo. Dentro da área de desenvolvimento pessoal, há o estímulo da tolerância, da paciência (Brook et al., 2007), resiliência, persistência, superação de adversidades (Thomas, 2002; Hudson \& Inkson, 2006), fortalecimento de valores éticos (Cook \& Jackson, 2006) e a capacidade de lidar com o stress (Thomas, 2002). Dentro de soluções de problemas são apontados maiores índices de inovação, criatividade (Thomas, 2002; Cook \& Jackson, 2006), adaptabilidade e engenhosidade (Thomas, 2002; Hudson \& Inkson, 2006; Brook et al., 2007). Há também o desenvolvimento de sensibilidade cultural (Hudson \& Inkson, 2006), maior poder de persuasão (Cook \& Jackson, 2006), negociação (Jones, 2005) e comunicação (Thomas, 2002). 
Para a perspectiva estratégica, a experiência voluntária contribui no desenvolvimento de uma perspectiva multicultural (Araujo et al., 2016; Thomas, 2002; Hudson \& Inkson, 2006; Brook et al., 2007). Ainda como resultado de aprendizado em experiências voluntárias, há a reflexão pessoal e o autoconhecimento (Brook et al., 2007), o aumento de habilidades de gestão, que podem ser entendidos como a capacidade de ensinar formalmente e informalmente (Bell, 1994; Thomas, 2002), mentoria e coaching (Cook \& Jackson, 2006), colaboração e trabalho em equipe (Jones, 2005; Brook et al., 2007), adquirem domínio técnico e prático da atividade que se propuseram a desempenhar (Hudson \& Inkson, 2006; Brook et al., 2007) e, por fim, a compreensão de ferramentas de desenvolvimento (Bell, 1994).

A Tabela 1 sintetiza os conhecimentos a respeito do estado atual da literatura sobre aprendizagem no exterior obtida por expatriados e por voluntários internacionais, conforme apresentado nos últimos três parágrafos.

\section{Tabela 1}

Resultados de pesquisas anteriores nos resultados de aprendizagem de expatriados e voluntários internacionais.

\begin{tabular}{|c|c|c|}
\hline & $\begin{array}{l}\text { Resultado de aprendizagem } \\
\text { comum a Expatriados }\end{array}$ & $\begin{array}{l}\text { Resultados de aprendizagem comum a } \\
\text { Voluntários Internacionais }\end{array}$ \\
\hline $\begin{array}{l}\text { Desenvolvimento } \\
\text { Pessoal }\end{array}$ & $\begin{array}{l}\text { Aumento de produtividade, } \\
\text { autossuficiência e confiança } \\
\text { (Bell, 1994; Thomas, 2002) }\end{array}$ & $\begin{array}{l}\text { Estimulo à tolerância, paciência (Brook et al., } \\
\text { 2007), resiliência, persistência, superação de } \\
\text { adversidades (Thomas, 2002; Hudson \& } \\
\text { Inkson, 2006), fortalecimento de valores } \\
\text { éticos (Cook \& Jackson, 2006) e a } \\
\text { capacidade de lidar com o stress (Thomas, } \\
\text { 2002) }\end{array}$ \\
\hline $\begin{array}{l}\text { Capacidade de } \\
\text { decisão e solução } \\
\text { de problemas }\end{array}$ & $\begin{array}{l}\text { Liderança e gestão de } \\
\text { incertezas (Thomas, 2002) }\end{array}$ & $\begin{array}{l}\text { Inovação, criatividade (Thomas, 2002; Cook } \\
\text { \& Jackson, 2006), adaptabilidade e } \\
\text { engenhosidade (Thomas, 2002; Hudson \& } \\
\text { Inkson, 2006; Brook et al., 2007) }\end{array}$ \\
\hline $\begin{array}{l}\text { Sensibilidade } \\
\text { Cultural } \\
\text { Comunicação }\end{array}$ & 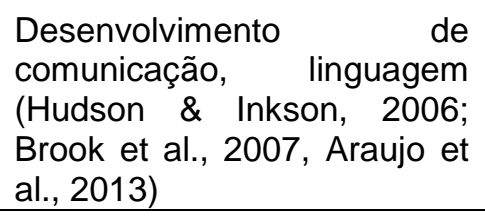 & $\begin{array}{l}\text { Sensibilidade cultural (Hudson \& Inkson, } \\
\text { 2006), maior poder de persuasão (Cook \& } \\
\text { Jackson, 2006), negociação (Jones, 2005) e } \\
\text { de comunicação (Thomas, 2002) }\end{array}$ \\
\hline $\begin{array}{l}\text { Perspectiva } \\
\text { estratégica }\end{array}$ & $\begin{array}{l}\text { Perspectiva e cidadania } \\
\text { global (Glass \& Westmon, } \\
\text { 2014; Thomas, 2002) }\end{array}$ & $\begin{array}{l}\text { Perspectiva multicultural (Thomas, 2002; } \\
\text { Brook et al., 2007) }\end{array}$ \\
\hline Autoconhecimento & & $\begin{array}{l}\text { Reflexão pessoal e o autoconhecimento } \\
\text { (Brook et al., 2007), o aumento de } \\
\text { performance e habilidades de gestão (Bell, }\end{array}$ \\
\hline
\end{tabular}




\begin{tabular}{|c|c|c|}
\hline & & 1994; Thomas, 2002) \\
\hline $\begin{array}{l}\text { Habilidades } \\
\text { Gerenciais }\end{array}$ & $\begin{array}{l}\text { Gestão de projetos, gestão } \\
\text { da diversidade (Cook \& } \\
\text { Jackson, 2006) }\end{array}$ & $\begin{array}{l}\text { Mentoria e coaching (Cook \& Jackson, 2006), } \\
\text { colaboração e trabalho em equipe (Jones, } \\
\text { 2005; Brook et al., 2007) }\end{array}$ \\
\hline $\begin{array}{l}\text { Domínio de um } \\
\text { conhecimento } \\
\text { específico }\end{array}$ & $\begin{array}{l}\text { Networking } \quad \text { profissional } \\
\text { (Cook \& Jackson, 2006) }\end{array}$ & $\begin{array}{l}\text { Domínio técnico e prático (Hudson \& Inkson, } \\
\text { 2006; Brook et al., 2007) e compreensão de } \\
\text { ferramentas de desenvolvimento (Bell, 1994) }\end{array}$ \\
\hline
\end{tabular}

Fonte: Fee, A., \& Gray S.J. (2011). Fast-tracking expatriate development: the unique learning environment of international volunteer placements. The international Journal of Human Resource Management, 22(3), 530-552. Adaptado pelos autores.

Portanto, há um grau relativo de conhecimento a respeito dos resultados de aprendizagem comumente obtidos em um contexto internacional voluntariado e a maneira pela qual o ambiente pode promover esse aprendizado.

\section{Metodologia}

\subsection{Método de Pesquisa}

O objetivo do presente artigo é compreender os resultados de aprendizagem obtidos no intercambio voluntário internacional. Este estudo explora as experiências e resultados do aprendizado descrito por voluntários regressos de seu IVI. O estudo qualitativo se mostrou o formato mais adequado para esta pesquisa exploratória, uma vez que permite atingir os detalhes requeridos para entender o contexto e suas influências (Ritchie \& Lewis, 2004).

\subsection{População e amostra}

Voluntários internacionais são diversos em termos de profissão, educação, idade, motivação e destino (Thomas, 2002). Dessa forma, um grupo heterogêneo de respondentes foi selecionado de uma organização sem fins lucrativos, gerida por estudantes do mundo, a AIESEC, presente em mais de 113 países e territórios.

No total, 25 voluntários brasileiros participaram da pesquisa. A duração dos intercâmbios voluntários variou entre seis e oito semanas e tiveram como destino 18 países diferentes. Eles se engajaram em projetos sociais locais com carga horária variável e atividades distintas, entre as quais, visitação de escolas, ensino de crianças, gerência de ONGs ou atividades ambientais. 


\subsection{Coleta de dados}

Os entrevistados foram contatados assim que retornaram de seus IVIs e convidados a participar de uma entrevista online, uma vez que residem em diferentes cidades. Três voluntários foram entrevistados pessoalmente, dada a facilidade geográfica. Não foi considerado o acompanhamento durante a viagem, uma vez que o tempo padrão de permanência dos entrevistados nos locais de intercâmbio foi curto, entre seis a oito semanas.

Para a coleta de dados, utilizou-se nas entrevistas uma variação da técnica de incidente crítico (Flanagan, 1954) que foca em situações de aprendizado e de mudanças pessoais. Essa técnica permite que os respondentes reportem suas experiências sem predeterminação do que é considerado importante.

O questionário consistiu em perguntas abertas que variaram de acordo com as respostas, e requereu dos respondentes detalhar uma situação em seu ambiente de trabalho que permitiu algum tipo de aprendizado. Tais perguntas incluíram o questionamento do que foi aprendido, o principal fato que gerou o evento, o contexto ou situação e como o aprendizado influenciou no trabalho. Os entrevistados também foram questionados sobre mudanças pessoais percebidas e sobre a performance no trabalho durante o intercâmbio. A Tabela 2 apresenta dados sobre as características dos respondentes.

\section{Tabela 2}

Características dos Respondentes

\begin{tabular}{l|c|c|l|c|c}
\hline & Observações & Percentual & & Observações & Percentual \\
\hline Curso & & & Nível de Educação & & \\
\hline $\begin{array}{l}\text { Negócios (Administração } \\
\text { e Economia) }\end{array}$ & 6 & $24 \%$ & $\begin{array}{l}\text { Pós-Graduação } \\
\text { Incompleta }\end{array}$ & 1 & $4 \%$ \\
\hline Comunicação Social & 7 & $28 \%$ & Graduado & 6 & $24 \%$ \\
\hline Relações Internacionais & 4 & $16 \%$ & $\begin{array}{l}\text { Graduação } \\
\text { Incompleta }\end{array}$ & 18 & $72 \%$ \\
\hline Letras & 2 & $8 \%$ & & & \\
\hline Tecnologia da Informação & 2 & $8 \%$ & & & \\
\hline Outros & 4 & $16 \%$ & $\begin{array}{l}\text { Idade na época do } \\
\text { Intercâmbio }\end{array}$ & & \\
\hline Gênero & & & $26-30$ & 1 & $4 \%$ \\
\hline Masculino & 10 & $40 \%$ & $22-25$ & 9 & $36 \%$ \\
\hline Feminino & 15 & $60 \%$ & $18-21$ & & \\
\hline Nota.Fon
\end{tabular}

Nota. Fonte: Elaborado pelos autores. 
O referencial teórico para a estrutura apresentada é baseado no modelo de aprendizagem informal e acidental de Marsick e Watkins (1990) e no efeito do aprendizado incremental de Eraut (2004).

\subsection{Técnica de análise dos dados}

As entrevistas semiestruturadas tiveram duração entre 15 e 40 minutos e os respondentes foram encorajados a discutir diversas experiências que consideravam relevantes. As entrevistas foram gravadas e transcritas.

A análise qualitativa foi feita manualmente. Frases significantes foram selecionadas e codificadas de acordo com os conceitos teóricos emergentes dos dados e temas encontrados na literatura.

Foi utilizada uma grade mista de codificação com códigos oriundos da literatura e códigos surgiram dos dados. Também foi utilizada a metodologia de análise de conteúdo, que consiste em uma ferramenta de análise para processar o material oriundo da comunicação verbal e não-verbal com os objetivos de superação da incerteza, enriquecimento da leitura (Bardin, 2011) e de facilitar a compreensão, interpretação e inferências dos resultados.

\section{Resultados}

No geral, foram reportados 119 eventos distintos de aprendizado. Todos os entrevistados reportaram ao menos 1 evento. Alguns entrevistados apresentaram mais de um evento para uma mesma área de aprendizado; para esses, apenas uma contagem foi computada. O máximo de contagens possíveis para cada área de aprendizado corresponde ao número total de entrevistados.

Todos os incidentes de aprendizagem encontrados puderam ser classificados nas oito categorias apontadas por Eraut (2004), embora tenha sido adotada a postura de abertura a eventuais novas categorias que poderiam emergir dos dados. Isso sugere que as categorias de Eraut (2004) alcançaram um nível satisfatório de saturação teórica.

A Tabela 2 sumariza o registro de eventos de aprendizado, agrupado segundo as categorias apresentadas por Eraut (2004). A primeira coluna apresenta as oito áreas de aprendizado, enquanto as outras duas colunas à direita representam o 
número total de incidentes e o percentual relativo ao número total de incidentes, respectivamente.

Como mostrado na Tabela 3, a principal área de aprendizado é a de desenvolvimento pessoal (1) $(21,0 \%$ de todos os incidentes), seguida por sensibilidade cultural (3) $(17,6 \%)$ e capacidade de decisão e solução de problemas (2) $(14,3 \%)$.

\section{Tabela 2}

Categorias de aprendizado

\begin{tabular}{l|c|c}
\hline & $\begin{array}{c}\text { Número de } \\
\text { Incidentes }\end{array}$ & $\begin{array}{c}\text { Percentual em relação ao } \\
\text { total de incidentes }\end{array}$ \\
\hline Área de Aprendizado & 25 & $21,0 \%$ \\
\hline 1. Desenvolvimento Pessoal & 17 & $14,3 \%$ \\
\hline 2. Capacidade de decisão e Solução de Problemas & 21 & $17,6 \%$ \\
\hline 3. Sensibilidade Cultural & 17 & $14,3 \%$ \\
\hline 4. Comunicação & 10 & $8,4 \%$ \\
\hline 5. Perspectiva Estratégica & 16 & $13,4 \%$ \\
\hline 6. Autoconhecimento & 9 & $7,6 \%$ \\
\hline 7. Habilidades Gerenciais & 4 & $3,4 \%$ \\
\hline 8. Domínio de um conhecimento Específico & 119 & $100 \%$ \\
\hline
\end{tabular}

Nota. Fonte: Elaborado pelo autor.

\subsection{Apresentação e discussão dos resultados}

\subsubsection{Contexto}

É importante notar que mais de $85 \%$ dos eventos que proporcionaram aprendizado ocorreu num contexto informal e acidental, fora do ambiente de trabalho. Apenas $3,4 \%$ do total de incidentes foi resultado de uma estrutura profissional de aprendizado. Isso permite sugerir que os voluntários estão mais propensos a aprender com as próprias iniciativas do que como agentes em uma estrutura profissional organizada.

O ambiente macro, o meio organizacional e as tarefas desempenhadas no IVI, conforme apresentado por Fee e Gray (2011), se mostraram ricos em termos de aprendizado. Todavia, neste estudo uma nova perspectiva foi exposta, ao contrário de resultados anteriores (Hudson \& Inkson, 2006; Fee \& Gray, 2011), em que parte do desenvolvimento é registrada como proveniente de diferenças como a alocação de jovens oriundos de países considerados desenvolvidos e outros que não possuem a mesma condição. 
A maioria dos voluntários (84\%) nunca havia saído de seu país e os recursos aplicados no intercâmbio são resultado de anos de economia durante o período de faculdade. Nesses casos, as condições econômicas do local de trabalho do país de destino e do país de origem eram bem similares, às vezes, os jovens trabalhavam em locais com melhor situação financeira do que a encontrada no país de origem.

A similaridade entre os valores do país de destino e o Brasil (país de origem) é pontuada com orgulho. Apesar das diferenças culturais e religiosas, muitos se surpreendem ao reconhecer, nos outros, valores muito próximos aos apresentados no país de origem. A similaridade, nesse caso, é interpretada como sinal de civilidade da cultura brasileira.

Quase todos $(80 \%)$ os respondentes já haviam trabalhado como voluntários no Brasil, e a escolha em fazer o trabalho voluntário internacional é apresentada como uma oportunidade de aliar o impacto positivo na comunidade com o desejo de conhecer outras culturas e idiomas.

\subsection{2 Áreas de aprendizagem}

Os 119 incidentes de aprendizado foram categorizados em 8 grandes áreas, conforme proposto por Eraut (2004). Os resultados mostraram que o 'desenvolvimento pessoal' foi reportado por 25 voluntários, ou seja, 25 incidentes, $21,0 \%$ do total de incidentes, a 'capacidade de decisão e solução de problemas' obteve 17 incidentes (14,3\%), 'sensibilidade cultural' obteve 21 incidentes $(17,6 \%)$, 'comunicação' obteve 17 incidentes (14,3\%), 'perspectiva estratégica' obteve 10 incidentes (8,4\%), 'autoconhecimento' obteve 16 incidentes (13,4\%), 'habilidades gerenciais' obteve 9 incidentes (7,6\%) e 'domínio de um conhecimento especifico' obteve 4 incidentes $(3,4 \%)$. Abaixo segue a explanação dos resultados de cada área.

\subsubsection{Desenvolvimento Pessoal}

O Desenvolvimento Pessoal é caracterizado pela capacidade do indivíduo de gerenciar diferentes emoções, a construção e a manutenção de relacionamentos, a habilidade de aprender com a experiência e o gerenciamento de si próprio (Eraut, 2004). Para essa área, todos os 25 voluntários reportaram um ajuste positivo de suas habilidades, competências e desenvolvimento pessoal. Os entrevistados sugerem que esse desenvolvimento foi possível graças à própria capacidade 
cognitiva, e que com a exposição cultural, incorporaram novos referenciais, melhoraram a compreensão de si próprios, agregaram diferentes perspectivas para uma tomada de decisão e aprimoraram a capacidade de análise crítica. Em outras palavras, na interpretação dos participantes, o aprendizado auferido foi em função, não somente do ambiente, mas da própria capacidade em assimilar e processar informações.

Quando questionada sobre a percepção de crescimento pessoal, o entrevistado 01, que realizou intercâmbio nas Ilhas Maurício, respondeu o seguinte:

Aumentei minha confiança - do ir e vir, melhorei minha comunicação. [O intercâmbio] me permitiu um aprendizado amplo. Hoje sei do que sou capaz, como me comporto quando tenho que conhecer pessoas novas e como lido com diferentes emoções. " - E01

O nível de choque cultural e as oportunidades para o desenvolvimento pessoal são funções, tanto das experiências prévias do indivíduo, quanto do país de destino. Os voluntários registraram percepções de crescimento pessoal diversas, como o entrevistado 02, estudante de Arquitetura, que viajou para a Rússia: "Hoje tenho menos medo das coisas. Aqui no Brasil, sempre que eu saia, eu tinha instruções do que fazer. No meu intercâmbio eu estava sempre arriscando. Tudo era novo". - E02

Foi possível verificar também que as pessoas identificam crescimento pessoal individual conforme o nível de maturidade e experiências prévias. Neste estudo, os participantes relataram que a primeira experiência internacional, independente do destino, gera percepções similares, enquanto as características do país de destino se tornam mais relevantes para o desenvolvimento pessoal conforme aumenta a maturidade internacional do indivíduo.

Para o baixo nível de maturidade do indivíduo, a percepção de desenvolvimento pessoal é positiva, independente do país de destino, enquanto, para indivíduos mais experientes, a percepção de desenvolvimento pessoal oscila com maior intensidade em função da distância cultural.

\subsubsection{Capacidade de Decisão e Solução de Problemas}

A Capacidade de Decisão e Solução de Problemas está relacionada com a exposição do voluntário na análise de problemas, no lidar com a complexidade do ambiente internacional, na tomada de decisões em grupo, na avaliação da 
necessidade de pedir ajuda, avaliação dos cenários e tomada de decisões sob pressão. Nesse caso, nem todos os eventos de aprendizado foram considerados agradáveis.

Muitas mudanças pessoais e a maturidade adquirida foram atribuídas a situações difíceis. Alguns entrevistados reconheceram as dificuldades como uma oportunidade de desenvolvimento de sua capacidade de decidir e solucionar problemas. Além disso, a maioria das situações e decisões relatadas como promovedoras da melhoria do poder de decisão são únicas do contexto de um IVI, e, dificilmente ocorreriam no país de origem. Conforme pode ser observado no trecho abaixo do entrevistado E03, estudante de T.I. (Tecnologia da Informação):

Eu tava indo da Bulgária para Ucrânia. Tava fazendo este trajeto de ônibus e daí eu atravessei pela Romênia - tudo tranquilo - aí quando eu fui atravessar a Moldávia, eles me pararam, porque eu não tinha visto, nem carta convite, nem nada. Daí não pude continuar a viagem. - E03

Ao solucionar o problema reportado acima, o entrevistado disse ter aprendido a ter calma na hora certa e refletir antes de tomar qualquer decisão, conforme relatado abaixo:

Então eu tive que pegar um taxi até uma cidade vizinha e de lá um trem para uma viagem que durou 27 horas. [...] Tem que ter calma na hora certa e a melhor coisa que a gente faz é sentar e dar um tempo. Esperar. Porque a ideia vem na sua cabeça e você consegue tomar a decisão acertada. Aprendi também a me informar um pouco mais, a não esperar que as pessoas me digam tudo." - E03.

A entrevistada 04, em seu intercâmbio de música na Itália, desistiu de seu projeto pela incompatibilidade entre as suas expectativas e as tarefas exigidas:

Eu falei que poderia vir pra cá [Itália] fazer mixagem, isso pra mim é tranquilo. Mas quando eu cheguei, eles disseram que eu deveria tocar algum instrumento em uma banda, e que as apresentações já estavam marcadas. Eu disse que não. - E04.

Neste caso, a decisão foi tomada em conjunto com os outros intercambistas do mesmo projeto. A decisão de desistir do projeto exigiu da entrevistada avaliar diferentes cenários, desde ter que voltar para casa a encontrar outro projeto com o qual possuísse afinidade. Neste caso, ela conseguiu ingressar em outro projeto:

... e aí surgiu a ideia de dar aulas de informática em uma ONG. E foi meio engraçado, sabe? Essa pra mim foi uma das melhores experiências. Por que eu não sabia nada e tive que "se" virar em mil, sabe? Além disso, tive que aprender Italiano para me comunicar com as crianças. Hoje sei que tomei a melhor decisão. - E04. 
Como resultado da experiência de solucionar problemas em contextos internacionais, os entrevistados reportaram melhor capacidade de gerenciamento de riscos em situações gerais. Isso porque os eventos do contexto internacional inserem novas variáveis ao escopo do intercambista.

\subsubsection{Sensibilidade Cultural}

Entender e interpretar o contexto internacional, assim como questões ligadas aos valores, são questões de Sensibilidade Cultural. O IVI permite ao voluntário desenvolver um conhecimento profundo não só do país de destino, como também o de ampliar a visão de mundo.

Em média, os voluntários conviveram (trabalharam ou moraram) com voluntários de pelo menos outras 7 diferentes nacionalidades, adquirindo conhecimento sobre outras culturas, experimentando o sentimento de pertencimento e o networking global. A absorção de outras culturas pode ser entendida pelo trecho abaixo, em que o entrevistado 05, estudante de Tecnologia da Informação, descreve sobre o Irã após ter convivido com uma voluntária Iraniana durante seu projeto na Polônia:

Então, o Irã é um país bem legal e tem uma história muito rica porque ele tem mais de 2 mil anos. Se você pegar a história, aquela região onde ele fica, é muito antiga, uma das primeiras civilizações começaram lá e a parte de geografia do país é muito bonita. Não existe só deserto como as pessoas pensam, existem montanhas, e o sul do país é rico em diversidades de beleza, patrimônios culturais muito ricos, e a própria sociedade em si é muito diversificada e aceita várias coisas. É claro que hoje para o muçulmano, existem várias regras, mas é um povo muito alegre, pelo que eu sempre vi após a minha viagem. Então, é um choque que eu acabei percebendo que o que eu li e o que ela (iraniana) me disse, é que me deixou bem a par que o que se fala não é de fato o que se é de verdade. - E05.

De uma maneira geral, os voluntários foram capazes de identificar diversas características culturais de seu país de destino, assim como expressar algumas palavras-chave no idioma local. Conforme apontado pelo entrevistado 06, outro voluntário da Polônia, estudante de Jornalismo:

... lá as pessoas trabalham um pouco diferente da gente, eles não trabalham de manhã e pausam pro almoço, enfim, é um pessoal que sempre gosta de estar reunido com os familiares e amigos. É um pessoal fechado, porém em 
algumas cidades do interior que visitei as pessoas são mais abertas, assim como aqui no nosso Brasil. - E06.

Para aqueles que estavam pela primeira vez no exterior, as percepções de diferença cultural partiram de observações dos hábitos do dia a dia, como mostrado no exemplo abaixo. Quando questionada sobre uma percepção de diferença cultural, a entrevistada 07, voluntária no Chile e estudante de Relações Públicas, mencionou:

... por exemplo, na família que eu morava e com todas que eu conheci eles não eram muito de jantar. Assim, por exemplo, a tarde, umas 7 horas, a gente tomava chá e comia pão. Isso era o dia inteiro. Sempre tomava chá. E depois não comiam mais. Eu vi como uma coisa familiar. - E07.

O aprendizado reportado pelos voluntários se apresentou em todas as regiões, mesmo onde há grande proximidade cultural como a América Latina. Porém, conforme apresentado abaixo pelo entrevistado 08, voluntário na Índia, as observações variam em escopo: "[A Índia] tem uma sociedade patriarcal e bastante machista, principalmente no norte. São muito apegados à religião e isso é motivo para muitas incoerências políticas e sociais". - E08.

Os voluntários internacionais foram capazes de identificar as características sociais dos países de destino; no entanto, não houve relatos de situações em que as atitudes foram moldadas pelo contexto e pelos valores locais.

\subsubsection{Comunicação}

Ter a oportunidade de trabalhar em projetos e morar em países onde a comunidade não fala inglês ou o idioma nativo, lugares onde a população não compartilha de uma mesma base educacional, política e religiosa, se apresenta como um ambiente propício ao desenvolvimento da capacidade linguística. Esse foi o caso de um voluntário estudante de Economia em seu intercâmbio na China, o entrevistado 09. Ao passar por um evento inusitado, ele teve de se comunicar de uma maneira alternativa:

Teve um dia que eu tava no trem lotado, já tava tarde e as pessoas às vezes olham pra você como se você fosse um alienígena. E tinha uma mulher do meu lado que não parava de pôr a mão em mim, me mostrando pra criança que tava no colo dela, eu me senti um pouco invadido, achei um pouco mal educado dela ficar pondo a mão em mim.... Eu falei pra ela parar, mas ela não entendia inglês, mas depois com a minha reação, fazendo cara feia, ela acabou entendendo.- E09. 
Dentro dos projetos, as equipes multiculturais permitiram ao voluntário aprender a se comunicar em um ambiente complexo, como foi o caso do entrevistado 05:

[Na minha equipe] tinha uma menina brasileira, dois da Bulgária, uma menina do Irã, um rapaz do Azerbaijão, uma menina da China, outra do Egito, uma menina do Vietnã e um rapaz da Turquia. No geral, a gente se comunicava bem, apesar de alguns não terem o inglês tão fluente. $O$ difícil mesmo era ter que lidar com o temperamento de alguns.- E05.

Os trabalhos em equipes multiculturais não exigiram tanto em termos de trabalho, uma vez que todos dividiam um mesmo nível educacional (nível universitário) e os projetos eram simples. As percepções e aprendizados se concentraram em questões comportamentais, como o de buscar diferentes formas de transferir uma mensagem.

\subsubsection{Perspectiva estratégica}

Aumento de desempenho, melhor gestão das prioridades e riscos são características relacionadas à Perspectiva Estratégica. Muitos voluntários tiveram o intercâmbio voluntário internacional como a primeira experiência no exterior, e o planejamento da viagem foi colocado como um desafio. A organização dos recursos escassos no dia-a-dia também foi pontuada, como relata o entrevistado 09, que voluntariou na China:

Bom, eu acho que por você estar num lugar tão diferente, em situações tão diferentes do que você vê aqui [Brasil], você tendo que se planejar pra sair de casa, pra ir no centro da cidade, já é um ponto positivo pra você, pra sua vida em si porque você não vai conseguir informação tão fácil, as coisas não vão ser mastigadas igual você pode conseguir no Brasil, além de eu também conseguir melhorar meu inglês. - E09.

Os voluntários tiveram a oportunidade de colocar em prática, de uma maneira alternativa, seus conhecimentos gerais e específicos. Devido ao curto período de tempo do trabalho voluntário, o planejamento estratégico foi importante para garantir a efetividade e a continuidade do trabalho executado. No caso do entrevistado 08 , estudante de Relações Públicas que fez seu trabalho voluntário na Índia, o trabalho de marketing e o reconhecimento da ONG exigem uma ação de longo prazo; neste caso, ele teve que criar ferramentas de controle. 
[Meu trabalho] consistia no desenvolvimento de soluções de marketing para aumentar o conhecimento e reconhecimento do trabalho da ONG. Mesmo não estando mais presente, criei um sistema para acompanhamento das campanhas. Consiste em acompanhar o número de visitas ao site, número de voluntários e do total de doações. Assim, os próximos voluntários podem acompanhar os resultados de suas ações - E08.

De uma maneira geral, os voluntários foram capazes de incorporar conhecimento e perspectiva global, além de uma visão estratégica mais sofisticada.

\subsubsection{Autoconhecimento}

Autoconhecimento é conhecer a si mesmo e entender os próprios limites. Dezesseis dos voluntários (64\%), reportaram como significantes a alteração ou o fortalecimento de seus valores e crenças durante o IVI. Isso possibilita momentos de reflexão e grande exposição a novas situações. O entrevistado 10, por exemplo, decidiu, durante o intercâmbio na Hungria, que deveria mudar de curso de graduação, pois encontrou na atividade voluntária, onde ensinava crianças, a verdadeira vocação.

O entrevistado 02, estudante de Jornalismo, em seu intercâmbio na Rússia, reportou compreender um pouco mais de si e desenvolveu certas características, conforme o trecho: "Eu acho que eu aprendi a ser mais tolerante, e sociável também, porque eu acho que eu não sou uma pessoa muito sociável. Aprendi a respeitar também as diferentes culturas e costumes". - E02.

Muitos intercambistas descreveram características próprias e como elas ficaram evidentes durante o intercâmbio. Além disso, desenvolveram a capacidade de identificar, reconhecer e absorver novas características pessoais e valores.

Eu gostava de entender o que as pessoas pensavam, então eu não conheci tantos castelos, tantos museus, porque isso tem todo ano. Então eu sempre tentava a todo momento conversar com pessoas, entender o que eles falavam, o porquê eles pensavam daquele jeito, afinal, aquela era minha chance de aprender com eles. Percebi que apesar das diferenças, somos todos parecidos em muitos aspectos. - E10.

Outro voluntário, em seu intercâmbio na Índia, fez a seguinte reflexão: "Sempre me considerei uma pessoa bastante independente e viver uma experiência tão independente me fez perceber que não necessariamente gosto de estar sozinho a toda hora".- E08. 
De uma maneira geral, além de reconhecer as próprias características e limitações, os voluntários foram capazes de reconhecer em si próprios características que precisavam melhorar.

\subsubsection{Habilidades gerenciais}

Habilidades gerenciais são capacidades genéricas de gerir pessoas, informações e projetos, por meio da liderança e da mentoria. Envolve também delegar, supervisionar e gerenciar crises (Eraut, 2004). Muitos entrevistados reportaram que o trabalho executado não exigia conhecimento específico. Ainda assim, é importante notar que eles se envolveram em atividades que dificilmente fariam no Brasil, adquirindo maior flexibilidade e compreensão de outras áreas. Além disso, muitos enfrentaram alterações de cronogramas e até mesmo foram alocados em projetos diferentes dos que haviam sido propostos originalmente, exigindo ainda mais flexibilidade e adaptação para desempenhar a função satisfatoriamente.

O entrevistado 11, estudante de Publicidade no Egito, citou ter aprendido a gerenciar crises como resultado de seu intercâmbio: "É uma experiência pessoal. Você se descobre em vários sentidos, eu faria tudo de novo. Foi uma experiência bacana e eu tenho certeza que hoje sei gerenciar crises". - E11.

Os recursos escassos em uma escola na África, por exemplo, exigiram do entrevistado 12 desenvolver um plano de arrecadação de fundos, conforme o seguinte trecho:

... depois de um tempo a gente começou a ver quais eram as maiores necessidades da escola. Eu, uma alemã e um mexicano. A gente combinou que íamos fazer campanha pra juntar dinheiro e a gente fez uma listagem de coisas que seriam mais importantes pra a escola.... no final das contas eu consegui juntar o dinheiro para o objetivo maior da gente, que era comprar o terreno pra a escola porque eles não tinham, eles pagavam aluguel, e ainda sobrou dinheiro pra comprar os materiais pra eles: caderno, livro, livro didático. - E12.

Nove entrevistados reportaram terem tido experiências por meio das quais puderam desenvolver liderança, gerenciamento de crises, priorização das tarefas e a lidar com questões éticas. 


\subsubsection{Domínio de um conhecimento específico}

O domínio de um conhecimento ou habilidade específica contribui para melhorar o desempenho em uma determinada tarefa. Está relacionado ao correto uso de evidências e argumentos, práticas de pesquisa, entendimento dos requisitos de trabalho e saber aliar a teoria à prática.

O curto período de duração do IVI mostrou-se um desafio para que os entrevistados fizessem treinamentos e reportassem algum aprendizado específico. Ainda assim, houve quatro casos de aprendizado específicos, como aconteceu com o voluntário 13, um estudante de Relações Internacionais em seu intercâmbio na Argentina. O respondente informou ter tido treinamentos para gerir o website de uma ONG.

Outros, por sua vez, aprofundaram o conhecimento que já possuíam, como foi o caso de um voluntário estudante de Letras (E10), que deu aulas de inglês para crianças Húngaras de várias faixas etárias. O principal motivo do intercâmbio, segundo os voluntários, no entanto, não é o de aprender algo específico relacionado à sua profissão, mas sim o da prática do inglês:

Escolhi esse projeto porque já trabalho com crianças desde os meus 12 anos, essa era a oportunidade perfeita para treinar meu inglês, aprender outro idioma e outra cultura fazendo uma coisa que eu gosto. A cultura russa sempre me encantou. - E10.

Em alguns casos, os voluntários colocaram em prática definições básicas de sua área de estudo, como foi o caso da entrevistada 14, uma voluntária bióloga em seu intercâmbio na Indonésia:

Teve uma parte de educação ambiental com crianças pequenas, que foi uma coisa bem simples, mas que requereu uma bagagem da minha formação. $E$ outra oportunidade foi em uma exposição aos alunos de nível médio. Teve a questão de resíduos que eu tinha uma maior facilidade por causa da minha graduação... - E14.

Por fim, um respondente em seu intercâmbio na Índia, relatou o seguinte: "boa parte do trabalho que desenvolvi na ONG está associado com minha graduação e na área que desejo atuar".- E08.

Sendo assim, segundo os voluntários, o intercâmbio voluntário internacional não é necessariamente um meio para realizar cursos ou aprender algo específico, 
mas sim um meio de aprendizado e desenvolvimento pessoal, além de uma oportunidade de aprender outro idioma e conhecer novas culturas.

\section{Considerações Finais}

\subsection{Conclusões}

Esse estudo visou compreender o quê indivíduos aprendem durante a experiência internacional de voluntariado. Os resultados corroboram a literatura no sentido de caracterizar o ambiente de voluntariado internacional como um rico meio de aprendizado e identificar as principais áreas de desenvolvimento reportado pelos voluntários.

Apesar de o trabalho voluntário estar inserido em um rico contexto que estimula o aprendizado, como proposto por Fee e Gray (2011), pouco se observou com relação ao desenvolvimento de conhecimento específico proveniente do ambiente de trabalho. Esse resultado não é necessariamente reflexo do curto período dos projetos, mas provavelmente da natureza e estrutura dos mesmos.

O estímulo à aprendizagem não garante a mesma. É um processo individual. O voluntário pode aprender ou reforçar crenças anteriores. O conteúdo de aprendizagem é dependente da relação entre cultura de origem e de destino, do grau de experiências prévias do voluntário, de sua motivação e características próprias, como capacidade cognitiva.

Muito do aprendizado reportado pelos voluntários neste estudo possui forte similaridade com estudos (Cook \& Jackson, 2006; Hudson \& Inkson, 2006; Brook et al., 2007; Fee \& Gray, 2011) que identificam habilidades críticas para futuros profissionais, como criatividade, capacidade de gerir incertezas e informações. Os jovens podem considerar os méritos de um IVI para o desenvolvimento de habilidades específicas e fortalecimento de seus princípios e valores. Além disso, obter aprendizado relevante em projetos voluntários de curto prazo se mostrou possível. Desta forma, com menor custo de oportunidade, tal atividade se mostra um caminho rápido para potencializar o aprendizado de competências.

Por fim, deve-se ter cautela, pois, apesar de o IVI se mostrar uma ferramenta eficiente para potencializar o desenvolvimento pessoal e profissional, o foco não deve se desviar da comunidade de destino e suas necessidades. Além disso, o conteúdo de aprendizado é diretamente proporcional ao envolvimento do voluntário 
com a comunidade de destino e, para estes, o IVI se apresenta como uma ótima oportunidade para promover o desenvolvimento pessoal e do outro, ao mesmo tempo que gera contribuição no contexto internacional.

\subsection{Limitações e sugestões para pesquisas futuras}

Este estudo apresenta as seguintes limitações: a pesquisa qualitativa permitiu coletar ricas informações sobre o aprendizado dos intercambistas; entretanto, este tipo de método limita a quantidade da amostra. Nesse sentido, é possível questionar a generalização dos resultados alcançados dado à baixa representatividade da amostra. A amostra representa apenas 1,5\% dos intercambistas brasileiros que viajaram pela AIESEC em 2013. No entanto, houve grande variedade dos países estudados, representando $16 \%$ do total de países onde a AIESEC está presente.

A proporção de voluntários do sexo feminino foi de $56 \%$ e apesar de estar coerente com estudos anteriores, este nível está acima do que é registrado em estudos com expatriados. Neste estudo não foi possível identificar diferença na experiência entre os gêneros. Todavia, o gênero pode influenciar a experiência que expatriados tem (Adler, 1987) e, neste caso, enviesar a proporção com que os diferentes tipos de aprendizado ocorrem.

Apesar da análise de aprendizado ter sido baseada em experiências, o que chamamos de aprendizagem, pode ser, na verdade, apenas a reprodução do discurso a respeito do que é esperado em termos de aprendizagem no exterior. A questão é a que todos os voluntários estavam em um período transitório de sua carreira. É possível que voluntários de curta duração sejam mais motivados a aprender, reportem mais experiência e, potencialmente, tenham um aprendizado distinto.

Para pesquisas futuras sugere-se a realização de um estudo longitudinal para melhor entendimento do desenvolvimento adquirido durante o intercâmbio. Assim, além de entender o progresso do voluntário, o estudo poderia realizar anotações de suas experiências. Sugere-se também que pesquisas futuras analisem somente dois países, para melhor determinar a diferença no conteúdo de aprendizado dos voluntários.

Gestores podem utilizar o IVI de curta duração como uma plataforma de desenvolvimento de seus funcionários. Tanto para candidatos à expatriação como 
funcionários que trabalham sob forte demanda, o IVI se apresenta como alternativa para o desenvolvimento de gestão de crises, resiliência, aumento de flexibilidade, além de aprender a importância de desempenhar múltiplas tarefas.

\section{Referências}

Adler, N. J. (1987). Pacific Basin Managers: A Gaijin Not a Woman. Human Resource Management, 26(2), 169-191.

AIESEC - Association Internationale des Etudiants en Sciences Economiques et Commerciales. (2014). Annual Report 2013. Rotterdan, Netherlands.

Arasaratnam, L. A., \& Doerfel, M. L. (2005). Intercultural Communication Competence: Identifying Key Components from Multicultural Perspectives. International Journal of Intercultural Relations, 29(2), 137-163.

Araujo, B. F. V. B., Broseghini, N., \& Fiorio, A. R. D. (2013). Suporte Organizacional e Adaptação de Cônjuges e Expatriados: uma análise por meio de Equações Estruturais. Revista Gestão e Tecnologia, 13(3), 51-76.

Araujo, B. F. V. B. D., Correa, F., \& Wolters, M. (2016). Is the American Accent an Advantage in Employment Decisions in Brazil? Revista de Administração Contemporânea, 20(6), 693-714.

Araújo, B. F. V. B., Teixeira, M. L. M., \& Malini, E. (2013). Estrangeirismo e Complexo de Gulliver: brasileiros na percepção de expatriados. Organizações \& Sociedade, 20(66), 461-477.

Bader, B., \& Schuster, T. (2015). Expatriate social networks in terrorism-endangered countries: An empirical analysis in Afghanistan, India, Pakistan, and Saudi Arabia. Journal of International Management, 21(1), 63-77.

Bardin, L. (2011). Análise de Conteúdo (70a ed.). São Paulo: Edições 70.

Bell, J. (1994). The Australian Volunteers Abroad Experience: Impact on Career Development. Australian Journal of Career Development, 3(3), 33-36.

Berlato, H., \& Corrêa, K. F. (2017) Uma Reformulação do Modelo Conceitual sobre Dual Career para Análise no âmbito Organizacional: Revelando Novas Vertentes. Brazilian Business Review, 14(2), 225-246.

Berthoin, A. (2000). Types of Knowledge Gained by Expatriate Managers. Journal Management of General, 26(2), 32-51. 
Black, J. S., Mendenhall, M. E., \& Oddou, G. (1991). Toward a comprehensive model of international adjustment: an integration of multiple theorical perspectives. Academy of Management Review, 16, 291-317.

Black, J. S., Morrison, A., \& Gregersen, H.B. (1999a). Global Explorers: The next generation of leaders. Nova York: Routledge.

Black, J. S., Gregersen, H. B., Mendanhall, M. E., \& Stroh, L. (1999). Globalizing People through International Assignments. New York: Addison-Wedley Publishing.

Bolino, M. C., \& Feldman, D.C. (2000). Increasing the skill utilization of expatriates. Human Resource Management, 39(4), 367-379.

Brook, J., Missingham, B., Hocking, R., \& Fifer, D. (2007). The Right Person for the Job: International Volunteering and the Australian Employment Market. Australian Volunteers International. Disponível em http://www.voced.edu.au/content/ngv\%3A65164

Cook, P., \& Jackson, N. (2006). Valuing Volunteering. London: Chartered Management Institute \& VSO.

Eraut, M. (2004). Informal Learning in the Workplace. Studies in Continuing Education, 26(2), 247-273.

Fee, A.; Heizmann, H.; Gray, S. J. (2015). Towards a theory of effective crosscultural capacity development: the experiences of Australian international NGO expatriates in Vietnam. The International Journal of Human Resource Management, 1-26.

Fee, A., \& Gray S.J. (2011). Fast-tracking expatriate development: the unique learning environment of international volunteer placements. The international Journal of Human Resource Management, 22(3), 530-552.

Flanagan, J. C. (1954). The Critical Incident Technique. Psychological Bulletin, 51(4), 327-358.

Glass, C. R., \& Westmont, C. M. (2014). Comparative effects of belongingness on the academic success and cross-cultural interactions of domestic and international students. International Journal of Intercultural Relations, 38, 106119.

Govindarajan, V., \& Gupta, A.K. (2001). The Quest for Global Dominance: Transforming Global Presence into Global Competitive Advantage. San Francisco, CA: Jossey-Bass.

Hudson, S., \& Inkson, K. (2006). Volunteer Overseas Development Workers: The Hero's Adventure and Personal Transformation. Career Development International, 11(4), 304-320. 
Jones, A. (2005). Assessing International Youth Service Programmes in Two Low Income Countries. Voluntary Action: The Journal of the Institute for Volunteering Research, 7(2), 87-100.

King, R., \& Raghuram, P. (2013). International student migration: mapping the field and new research agendas. Population, Space and Place, 19(2), 127-137.

Lee, L., \& Sukoco, B. M. (2010). The effects of cultural intelligence on expatriate performance: The moderating effects of international experience. The International Journal of Human Resource Management, 21(7), 963-981.

Lyons, K., Hanley, K., Wearing, S., \& Neil, J. (2012). Gap Year volunteer tourism: Myths of global citizenship?Annals of Tourism Research, 29(1), 361-378.

Marsick, V. J., \& Watkins, K. E. (1990). Informal and Incidental Learning in the workplace. Londres: Routledge.

Nascimento, R. C. (2012). Turismo e Voluntariado: Um estudo sobre as publicações em revistas científicas nacionais e internacionais. Turismo em análise, 23(2), 265-285.

ONUBR - NAÇÕES UNIDAS NO BRASIL. (2013). Programa de Voluntários. Recuperado de http://www.onu.org.br/onu-no-brasil/pnud/vnu/.

Polonijo-King, I. (2004). In Whose Words? Narrative Analysis of International Volunteer Stories from an Anthropological Perspective. Croatian Journal of Ethnology and Folklore Research, 41(1), 103-123.

Reis, G. G., Fleury, M. T. L., Fleury, A. C. C., \& Zambaldi, F. (2015). Brazilian Multinationals Competences: Impacts of a" Tug of War" Between Cultural Legacies and Global Mindedness. Brazilian Business Review, 12(1), 55-79.

Ritchie, J., \& Lewis, J. (2004). Qualitative Research Practice: A Guide for Social Science Students and Researchers. London: Sage.

Ryan, A., Boyce, A., Ghumman, S., Jundt, D., Schimidt, G., \& Gibby, R. (2009). Going global: Cultural Values and Perceptions of Selection Procedures. Applied Psychology: An International Review, 58(40), 520-556.

Santos, N. M., Bronzo, M., Oliveira, M. P. V., \& Resende, P. T. V. (2014). Organizational Culture, Organizational Structure and Human Resource Management as Bases for Business Process Orientation and their Impacts on Organizational Performance. Brazilian Business Review, 11(3), 100-122.

Shen, J., \& Jiang, F. (2015). Factors influencing Chinese female expatriates' performance in international assignments. The International Journal of Human Resource Management, 26(3), 299-315. 
Simpson, K. (2004). Doing development: The gap year, volunteer-tourists and a popular practice of development. Journal of International Development, 16(5), 681-692.

Sippola, A., \& Smale, A. (2007). The global integration of diversity management: A longitudinal case study. The International Journal of Human Resource Management, 18(11), 1895-1916.

Tran, L. T., \& Nyland, C. (2013). Competency-based training, global skills mobility and the teaching of international students in vocational education and training. Journal of Vocational Education \& Training, 65(1), 143-157.

Thomas, D.C., \& Inkson, K. (2003). Cultural Intelligence: People Skills for Global Business. São Francisco, CA: Berrett-Koehler.

Thomas, G. (2002). Human Traffic: Skills, Employers and International Volunteering. Technical: Demos.

Van Woerkom, M., \& Reuver, R.S.M. (2009). Predicting excellent management performance in an intercultural context: A study of the influence of multicultural personality on transformational leadership and performance. The International Journal of Human Resource Management, 20(10), 2013-2029.

von Borell de Araujo, B. F., Teixeira, M. L. M., da Cruz, P. B., \& Malini, E. (2014). Understanding the adaptation of organizational and self-initiated expatriates in the context of Brazilian culture. The International Journal of Human Resource Management, 25(18), 2489-2509.

Wilson, J. (2000). Volunteering. Annual Review of Sociology, 26, 215-240. 